\title{
ASCO’s Clinical Practice Committee
}

\section{"The sands are number'd that make up my life ..." Shakespeare}

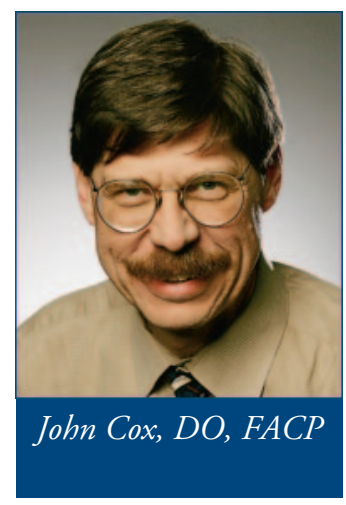

By John V. Cox, DO, FACP

The median age of medical oncologists in the US is 53 years old. My age. I am one of seven medical oncologists at my practice site; only two are under 50 ; three are more than 63 years old. All of us are attached to our work. It is easy to find meaning in our profession, as it is an exciting time to work in oncology. What we do clearly "matters." Yet, as a group, we are a bit tired. Whether we admit it or not, we all had scenarios of our lives that included branching out a bit, maybe taking that extra course about Shakespeare, and slowing down.

Instead, our practice demands more of us than ever before. With advancing and rapidly changing science, we must keep up. To do this requires increasing discipline. As well, the "rules" that govern our practice seem to grow more complicated yearly. Documentation and the increasing role of technology in our daily work add challenges to the older physicians in our group. "Incident to" rules require our presence in the office, extending our hours; and with multiple sites of service to be covered, we must "serve" a complex schedule.

For all of these reasons, and more-our practice is actively recruiting new, young oncologists to join us. This process has brought about other realities. Primary of these is the fact that there is a limited pool of applicants. Approximately 450 new medical oncologists complete their training each year. From that number academic and community practices will compete to fill positions.

This experience is being replayed across the country. As chair of the Clinical Practice Committee (CPC), I have spoken to multiple state societies over the last year. I often ask attendees "who is actively recruiting or will recruit in the next two years?" Inevitably, everyone in the room will raise their hand. What looms is a crisis as the supply of new oncologists remains constant, while the current generations age and retire. At the same time the general population is aging, with a rising number of cancer patients who wish to tap the ever-improving, more effective therapeutics—increasing the need for what we do.

The other side of this coin is that it is a good time to be a young oncologist. Wherever one wants to practice there will be an opportunity. But here too lies a role for ASCO. Ironically, these young physicians are facing increasing challenges brought about by many choices. They are making life choices with few resources to call upon to help them with decisions. Do they stay in academics or go into private practice? If academics, what are the pitfalls of that world? And if practice, how does one evaluate a particular organization? Small group or large group? Institutional employment? Whatever the choices, how does one evaluate a contract? Whom does one ask for help?

At our annual meeting, ASCO has provided a bit of insight into some of these issues, but we have not developed a systematic or robust set of resources that young oncologists can call upon for aid. As these young physicians are our future, our organization should do more.

Both sides of this issue were highlighted at CPC meetings this spring. Our committee heard an interval report from Dr. Michael Goldstein concerning the ASCO Workforce Study. Ongoing is a survey of our membership to get a better handle on the demographics of oncology and "our" attitudes towards work. Be alert at the ASCO meeting this year to hear more, and watch for publication of this report. It will provide insight that will allow us to develop better coping strategies.

As well, the $\mathrm{CPC}$ is actively collaborating with the Career Development Committee to enlarge upon the resources that Fellows can call upon to learn about all aspects of careers in oncology. The goal is not only to provide clear and complete descriptions of the many areas of work available, but also to provide an array of practical tools that trainees can use-tools that will include information about contracts, pitfalls in organizations of which to be aware, information about advisors that need to be consulted, and others. Elsewhere in this issue, the JOP is initiating a series of articles to highlight aspects of this quest. As well, the Career Development Committee is working to develop a comprehensive resource for Fellows. It is envisioned that this will be a resource that will be regularly updated and be tied to the annual meeting's educational efforts. Another area ASCO is exploring is the issue of mid-career changes. Many mature oncologists change from academic to community practice and vice versa. These ASCO members are seeking advice as well. CPC members, especially Dean Gesme, MD, have been actively engaged in leading this effort.

The science of oncology is rapidly expanding our capabilities. ASCO is providing a voice to respond to both aspects of this 
generational crisis. I hope to see my practice renewed by a young spirit, and have time to appreciate Shakespeare!

I have had the privilege to write this column over the last year. With this issue, I turn the pen over to Peter Paul Yu, $\mathrm{MD}$, incoming chair of the CPC (see the feature on Dr. Yu in this issue). The JOP is giving voice to important issues affecting our profession, and using the discipline of science to illuminate them. Congratulations on a wonderful first year to Dr. Doug Blayney and his staff at the JOP.

John V. Cox, DO, FACP, is in private practice of hematology-medical oncology in Dallas, Texas, as a partner of Texas Oncology PA. He is currently serving as chair of ASCO's Clinical Practice Committee.

\section{Have you registered? Coming in June...}

\section{The 2006 ASCO Annual Meeting and Best of ASCO Meetings}

Join the world oncology community at the 2006 ASCO Annual Meeting. Get the latest scientific findings and practice-changing advances in cancer prevention and treatment.

June 2-6, 2006

Atlanta, Georgia

Register at www.asco.org/annualmeeting.

Can't attend the Annual Meeting? Try a Best of ASCO Meeting, in one of two convenient coastal locations. These $1 \frac{1}{2}$ day educational events feature premier abstracts from the 2006 ASCO Annual Meeting.

June 16-17, 2006

Beverly Hills, California

Register at www.asco.org/boa2006.
June 23-24, 2006

Reston, Virginia (near Washington DC)

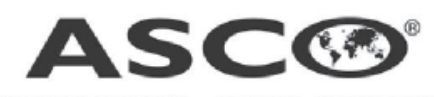

AMERICAN SOCIETY OF CLINICAL ONCOLOGY 